\title{
Identity Management Strategies Among Sexual Minority Students in Tsinghua University
}

\author{
Chunhong Liu \\ Institute of Education, Tsinghua University, Beijing, China
}

Email address:

1ch19@mails.tsinghua.edu.cn

\section{To cite this article:}

Chunhong Liu. Identity Management Strategies Among Sexual Minority Students in Tsinghua University. Psychology and Behavioral Sciences. Vol. 10, No. 3, 2021, pp. 112-120. doi: 10.11648/j.pbs.20211003.12

Received: March 1, 2021; Accepted: May 10, 2021; Published: May 24, 2021

\begin{abstract}
In China, coming out can bring bad consequences, so sexual minorities have the option to show or hide their sexual orientation. On campus, there are some kinds of identity management strategies for students from sexual minorities. In order to study when the LGBTQ community in Tsinghua University chose open sexual orientation and the relationship with its reasons in the campus environment, this study uses an in-depth interview method to study the identity management strategies of seven participants. The study sorted out and analyzed the interview records. After analysis, the seven participants adopted a total of three identity management strategies. They are respectively: explicitly coming out strategy, impersonation strategy and implicitly coming out strategy. Two participants adopted explicitly coming out strategy, two adopted implicitly coming out strategy and other three adopted impersonation strategy. For the choice of identity management strategy of the students, the contact with the environment and the assessment of the risks play an important role. Apart from this, with the development of the Internet, there have also been new developments in the identity management strategies of the gender minorities on campus in the Internet social apps. The identity management strategy on the Internet is different from reality. Students' assessment of risk and perception of the environment are different. It may be a brand-new strategy.
\end{abstract}

Keywords: Gender Identity, Identity Management Strategies, Sexual Minority Students

\section{Introduction: Coming out Is Still Difficult Now}

In the modern sense, "coming out" refers to the process by which sexual minorities complete their self-identity and express their sexual orientation to others. However, the meaning of "coming out" has undergone a subtle reversal process since the beginning of the 20th century. The subject has completed a complete transformation from the homosexual world to the heterosexual world. More specifically, "coming out" refers to the process of accepting that you are a sexual minority and integrating this sexual identity / orientation into your individual life. This contains two dimensions: self-identification of homosexual orientation and expressing this sexual orientation to others. It is also a process in which homosexuals create themselves. Through an evolving process, homosexuals recognize their sexual preferences and integrate this awareness into them personal and social life. This process is also their identity management process, because different people have many important experiences, such as the awakening of sexual attraction, the first sexual experience, appeared in the homosexual world, and chose different identity management Strategy, many sexual minorities need to be carefully prepared and constantly tested when choosing an identity management strategy in order to minimize damage and risk.

As a sub-cultural group, Sexual minorities has always been affected by social stigma, but homosexuality, as an objective existence in history, already has its own unique values, habits and behavioral norms. According to reports, the number of sexual minorities in China is about 272010,000 people. But until today, they are still a large and independent marginal group, which also affects the healthy development of homosexuality, family and society to a certain extent. Due to historical and cultural reasons, the study of sexual minorities in Chinese society Compared with the West is relatively scarce. Under the constraints of many cultural and practical factors such as Confucian ethics, relationship orientation, filial piety, and family nurturing and nursing models, Chinese 
sexual minorities often suffer from their identity management, and they gradually formed Own strategies. Therefore, the study of self- identity management strategies for sexual minorities has profound social significance and the dilemmas they face.

\subsection{Foreign Research}

Self-identity (identity) sums total of being's knowledge and understanding of his or herself. Integral part of self-identity are physical, psychological, and social attributes. They may be influenced by the individual's attitudes, habits, beliefs and ideas. [1]

Psychologists Carl Rogers and Abraham Maslow had major influence in popularizing the idea of self-concept in the west. According to Rogers, everyone strives to reach an "ideal self". Rogers also hypothesized that psychologically healthy people actively move away from roles created by others' expectations, and instead look within themselves for validation. On the other hand, neurotic people have "self-concepts that do not match their experiences. They are afraid to accept their own experiences as valid, so they distort them, either to protect themselves or to win approval from others." [2]

The self-categorization theory developed by John Turner states that the self-concept consists of at least two "levels": a personal identity and a social one. In other words, one's self-evaluation relies on self-perceptions and how others perceive them. Self-concept can alternate rapidly between the personal and social identity. [3]

Self-identification is associated with many things. Research has established a clear link between racial and ethnic identities and academic success: some identities are positively associated with academic success (white), and some are negatively associated with academic success. [4-6]

Individuals who self-identify as LGBT can face a number of challenges. Presenting problems that face LGBT individuals, couples, and communities include barriers to same-sex marriage, adoption, health care, employment discrimination, violence, bullying, alienation, isolation, suicidal ideation, and the potentially daunting process of "coming out" to family and friends (Barret \& Logan, 2002). [7] Congruence between sexual behavior and preference in the USA sample was negatively correlated with psychological distress. [8]

Self-identification is even harder for LGBT. The Marginal Man Framework indicates that multiracial individuals may not identify with any racial/ethnic group because they do not experience full acceptance by either group, although the contrasting social identity theory suggests that individuals' identities simplify as they age, perhaps in response to social pressure for conformity. [9]

Studies utilized qualitative methodology due to the difficulty of collecting data on a large scale. Ian Rivers and Cesar Gonzalez (2018) study draws on in-depth interviews with 17 LGBT individuals living in England, and explores the narratives used by participants to better understand their perceptions of risk and protective circumstances to explain suicide attempts in youth. [10] Cole Carolyn and Harris Helen used a phenomenological qualitative methodology to explore a range of lived experiences of seventeen adult men and women who self-identify as LGBT and Christian [11]

\subsection{Domestic Research}

In the study of self-identity of sexual minority groups, both domestic and foreign research have experienced a process of rising volatility. From the perspective of social acceptance, foreign research on self-identity of sexual minorities started earlier and development is relatively perfect. Based on the diversification of China's history, culture, law, and social ideology, China has not yet formed a legal system related to sexual minorities. The affirmative movement of sexual minorities has not attracted much attention. Relatively speaking, China's self-identity of homosexual groups lacks certain focus and research. The current research on homosexual identity is still in its infancy, and many discussions on sexual minorities still remain in pathological causes and solutions, mainly in sociology, medicine and psychology, while the main research issues are focused on homosexuality. The causes and therapeutic effects of the sexual minority groups are rarely studied or explored in separate literatures or chapters. Therefore, relevant research should be done in the future to minimize the discussion of the causes of sexual identity, but to focus on the psychological basis of homosexual identity and the corresponding support methods.

As far as the gay community is concerned, self-identity is a concept that spans psychology, sociology, and ethics. In layman's terms, identity is "who am I" and "what should I do". In the concept of self-identity, Zhang Beichuan believes in homosexuality that homosexuality means that under the condition that the choice of a sexual partner is fully free, a sexually mature individual may have obvious or strong sexual orientation toward the same sex or at the same time. There are active homosexual behaviors that can be considered as homosexuals." [12] He distinguishes between homosexuality and homosexuality. True homosexuality is the result of voluntary choice of sexually mature individuals. Occasionally, same-sex behavior is not homosexuality, which provides a basis for homosexuals to realize self-awareness.

Many scholars use empirical research to explore the self-identity of sexual minorities. Shi Guozheng and others explored gay identity status and related influencing factors through an empirical analysis of 459 men who have sex with men in Shanghai. They divided gay identity into positive identity and negative identity. The results showed that $53.2 \%$ held negative self-identification and $48.1 \%$ held negative identity in personal identity; and social identity actively recognized the group. The corresponding personal identity is positively recognized. [13] $\mathrm{Li}$ Yinhe (2002) two social studies "The Feelings and Sex of Chinese Women" [14]And "Gay Subculture" [15]In the process of collecting a large number of homosexual cases and conducting academic analysis, she believes that homosexual identity is divided into two types: one is self-communication, natural and 
homosexual; the other is at a certain key. At the moment, he was guided by others and learned to have sex with the same sex, and proposed the theory of "blank occupation".

In addition, many scholars have also established a model of homosexual self-identity, Liu Dalin, Lu Longguang believes that "identity perception - identity confusion identity presupposition - identity fixed" is the four homosexuals to achieve self-identity stage. [16] Yang Ling and Xie Yuanjun explored the development of gay men's self-identity in his article "Quality Research on the Development of Gay Men's Self-identity". They believe that "same-sex attraction, self-labeling (ie, confirming their homosexual orientation), same- sex sexual contact, and self-disclosure (ie, informing others about their homosexual identity) are the main stages of their self- identification. Zhou Lingang (2005) believes that homosexuals also define themselves through others. Although they try to be selfaffirmative, they cannot surpass the concepts imposed by the outside world. Just as symbolic interaction theory puts forward that our self-recognition is determined by others' evaluation of us, so the social identity of homosexuality will inevitably affect their self- identity. [17] Zhang Peifei (2014) proposed that homosexual self-identity is not only the process of constructing one's own identity, but also the social identity process of homosexuals in society, and self-identity and social identity will affect the whole life process of homosexuals. [18]

\section{LGBTQ Youth Adopt Many Identity Management Strategies}

According to Contextual constraints and choices Strategic identity management among LGBTQ youth. In total, 41 (89\%) of LGBTQ young adults utilized context-specific strategies to manage their identities as they transitioned across social interactions and environments. They further refined and tailored these strategies as they navigated their identity in more salient relationships they deemed important in their lives.

One key way that both LGBTQ college and homeless young adults strategically managed their identities was through identity concealment, which operated internally and externally.

Besides, LGBTQ youth adopt varied behaviors to manage their marginalized identities, such as relying on situational assessments, which can result in a "revolving door" of contextual identity disclosure processes [19]. "Strategic outness" considers how individuals utilize an "identity management system" to continually control information surrounding their sexual identity.

Most notably, both college and homeless young adults faced challenges in determining how to disclose their identities to various family members. About Agency within identity Glass gold summarized the importance of agency among LGBTQ people: "Agency is an attempt to live as authentically in the world as we can, given its restraints and limits; and it occurs when we commit to meeting each limit with resistance, then finding a creative solution to transcend that limit." Despite facing prejudice and discrimination, young people stablished control over when and how they disclosed their identity, thus highlighting their sense of autonomy. Transgender individuals, meanwhile, must contend with more public scrutiny surrounding gender expression and the policing of gender expansive displays, which can hinder their ability to strategically manage their identities in ways that promote well-being.

Through the practical investigation in the article, we can know that Several young people described agentic processes that were heavily tempered by structural constraints, such as perceptions of negativity that encouraged them to conceal or minimize their identities, and Several young people mediates their identity through her presentation of self that she uses to draw from her privileged social statuses. Finally, there are some people who manage their identity through self-suggestion and self-deception. By relegating their gender and sexual identity to a status that does not define who they are, LGBTQ college students exerted agency in their lives and social relationships.

The strategies and agency LGBTQ young people exhibit as they manage the impact of identity within their lives underscores their ability to adapt to diverse social contexts and relationships. Many LGBTQ young adults concealed their identities when they deemed it prudent and most participants consciously strategized identity disclosure depending on the social interaction. While both college students and homeless young adults found ways to exert agency within their identities, social context shaped their perceptions as college students adopted an empowered framework, while homeless young adults displayed pragmatic approaches to their LGBTQ identity. LGBTQ young people's emphasis on the influential role of social context in shaping their strategic identity management highlights the importance of a social ecological framework in examining the multiple spheres of influence on youths' experiences.

Pat Griffin, a professor emeritus at the University of Massachusetts, published a classic study in 1991 in the International Journal of qualitative research in education, revealing the identity management strategies of gay teachers in the United States.

The "impersonation" strategy refers to leading others to believe that they are heterosexual. "Impersonation" can be divided into "active impersonation" and "passive impersonation". "Active impersonation" is intended to make others believe that they are heterosexual through words and actions. "Passive impersonation" means letting people acquiesce that they are heterosexual and do not correct it.

The second identity management strategy is "covering", that is, trying to hide their homosexual identity. This is an important difference from the "impersonation" strategy, because compared with the "impersonation" strategy that intentionally misleads others to think that they are heterosexual, "cover up" means not intentionally cheating 
others, and more close to honesty.

The third strategy is "indirect coming out", which means that although homosexual students do not directly disclose their identity, they are known to be homosexual. It has advantages and disadvantages for gay students to come out indirectly. There are two main benefits: first, homosexual students can get a certain degree of security, because their homosexual identity is not directly open; second, compared with the two strategies of "pretending" and "covering up", students who come out indirectly feel more honest in their hearts, and do not need to lie or do too much self-examination.

"Explicit coming out" is the fourth strategy of identity management of homosexual students, which means that homosexual students use the words "gay" or "lesbian" to directly disclose their identity. All the gay students in the study thought that going out directly was a high-risk behavior. Therefore, making this decision requires careful consideration and preparation. Homosexual students will carefully choose trustworthy objects for going out, because after going out directly, homosexuality becomes a secret that needs to be kept by two people. Some gay students believe that going out to colleagues who are also gay is just as risky as going out to heterosexual colleagues. They think homosexual colleagues who are completely in the closet may not be trustworthy and will sell themselves in order to transfer people's doubts about their identity. In addition, gay students think it's more difficult to come out to students than to colleagues. Despite the high risk of going out directly, gay students still want to be able to directly disclose their identity, because going out directly can protect them from camouflage, maintain honesty, and integrate professional identity and personal identity. Direct exit strategy can also avoid the uncertainty of indirect exit strategy. Going out directly to some people in the school can reduce the alienation of homosexual students in the school and get support when necessary.

\section{Research Method and Process}

\subsection{Research Method}

The aim is to understand the identity management strategies adopted by LGBTQ groups at Tsinghua University and the reasons behind them. Therefore, this research approach is integration analysis of using the literature and deep interview. Researchers search for identity management strategies that have been proposed through literature analysis. Then through in-depth interviews to explore the strategies used by the study participants and compare the results with the literature. In-depth interviews are used because in-depth interviews help to better explore deeper reasons, and it is difficult to collect data on a large scale.

\subsection{Research Process}

All our participants came from PURPLE --homosexual community in Tsinghua University. There are 175 members in the community. On October 11, 2019, researchers posted a message to recruit participants in PURPLE's WeChat group. A total of 7 participants actively contacted the researchers to participate in the trial. After coordination, researchers and participants identified one-on-one in-depth interviews. During the one-month period, the three researchers interviewed each of the seven participants face-to-face, and recorded them after soliciting their consent.

Table 1. Continuum of identity management strategies used by lesbian and gay students.

\begin{tabular}{|c|c|c|c|c|c|}
\hline Totally Closeted & passing & covering & Implicitly out & Explicitly out & Publicly out \\
\hline \multirow{3}{*}{$\begin{array}{l}\text { Out to no one at } \\
\text { school }\end{array}$} & lying & censoring & $\begin{array}{l}\text { Telling truth not gay } \\
\text { /lesbian labels }\end{array}$ & $\begin{array}{l}\text { Affirming lesbian/gay } \\
\text { identity }\end{array}$ & \multirow{4}{*}{$\begin{array}{l}\text { Out to school } \\
\text { community }\end{array}$} \\
\hline & $\begin{array}{l}\text { I assume you do not } \\
\text { know }\end{array}$ & $\begin{array}{l}\text { I assume you do not } \\
\text { know }\end{array}$ & $\begin{array}{l}\text { I assume you know, but I } \\
\text { am not sure }\end{array}$ & $\begin{array}{l}\text { I know you know. you know } \\
\text { I know you know. }\end{array}$ & \\
\hline & See me as heterosexual & $\begin{array}{l}\text { Do not see me } \\
\text { lesbian/gay }\end{array}$ & $\begin{array}{l}\text { You can see me as } \\
\text { lesbian/gay if you want to }\end{array}$ & See me as lesbian/gay & \\
\hline separation & & Personal/professiona & & integration & \\
\hline
\end{tabular}

\section{Three DIFFERENT Strategies Adopted by LGBTQ Students in Tsinghua University}

Participants are detailed in the table below.

Table 2. Details of Participants.

\begin{tabular}{|c|c|c|c|c|}
\hline NUMBER & GENDER & IDENTITY & GRADE & INTERVIEW HOUR \\
\hline G1 & female & Queer & Second year of Postgraduate & 3 hours \\
\hline B1 & male & Gay & Second year of Undergraduate & 2 and a half hours \\
\hline G2 & female & Lesbian & Second year of Undergraduate & 1 hour and 50 minutes \\
\hline B2 & male & Gay & Second year of Undergraduate & 1 hour and 10 minutes \\
\hline G3 & female & Queer & Second year of doctoral students & 40 minutes \\
\hline B3 & male & Gay & Second year of Undergraduate & 2 hours \\
\hline B4 & male & Gay & Second year of Undergraduate & 2 hours \\
\hline
\end{tabular}


After analysis, the seven participants adopted a total of three identity management strategies, namely: explicitly coming out strategy, impersonation strategy and implicitly coming out strategy.

\subsection{Explicitly Coming Out Strategy}

In Tsinghua University, homosexual students use more euphemism to express their identity. Such as "I am not straight." and "I like boy." Due to the stigma of gay labels in Chinese society, some of subjects avoided using "gay" or "lesbian" to describe their self-identity, even one of them said "I hated use the g-word and didn't want to say it clearly." We think that as long as participants express their sexual orientation in clear language, they can be considered to have adopted an explicitly coming out strategy. After the participants come out to the trusted person, the two will assume that this is a shared secret.

As we can see, two participants adopted explicitly coming out strategy. Of all seven participants, two participants chose to come out to friends, roommates, and classmates. Another participant came out to only his homosexual friend in same school. Other participants have not adopted explicitly coming out strategy on university campuses. Although living in a modern and open university, many teachers or classmates still have great prejudice against sexual minorities. In the case of uncertain attitudes towards the homosexuality of the teachers or classmates they are facing, few participants are willing to choose to explicitly coming out.

Participants evaluate the risks of coming out of different people before making a choice. Even participants who adopted explicitly coming out strategy had different risk assessments for coming out to different people. Different participants judge the risks of explicitly coming out differently, either. Overall, female participants thought the risks were lower than men. On university campuses, students deal with many aspects of relationships. For example, teachers, school staff, roommates, classmates, friends met in interest groups, students in student union organizations, and students in the minority group--PURPLE.

TEACHER AND SCHOOL STAFF: Everyone consider it very risky to come out publicly to a teacher or school staff. In our study, participants excluded their teachers when they selected their coming out subjects, they all agree that explicitly coming out to the teacher is an impossible option.

ROOMMATES: Coming out to roommates is considered the highest risk and the most difficult. Since college students all live-in dormitories, whether or not roommates accept their sexual orientation greatly affects their daily lives. The roommates of the two female participants accepted their sexual orientation very well and actively offered advice and help in their relationships. But the two participants also told the story that other lesbians were not accepted by their roommates but ignored or bullied. In light of these potential risks, male participants have stated that they will not come out to their roommates, and in particular they will avoid displaying homosexuality in the face of roommates who show offensive sexual minority groups.

MINORITIES GROUP: There are many groups of sexual minorities in schools, and it is considered safe to adopt explicitly coming out strategies in these groups. One of the participants (24-year-old queer) reported that she had found her sexual identity in the school basketball team, and all members of this basketball team are lesbian. In the basketball team, heterosexuality is the minority group. "Everyone on the basketball team is lesbian, and lesbian is normal.", she said. Lesbians do not have to worry about being discriminated at all, and they can freely discuss content related to LGBTQ. There is a sexual minority community in Tsinghua University called Purple, all our participants are members of the community. When members join the community, they will explain their sexual orientation to the principal of the community. Therefore, all members of the community adopt explicitly coming out strategy. Members of the community will keep each other secret by default, and do not share the sexual orientation information of members with people outside the community.

INTERNET: Participants use social dating software for sexual minorities. They use explicitly coming out strategy on dating software, but they do not expose or rarely reveal their true information. Gays use BLUED and lesbians use RELA to look for a date. In addition to social software, some WeChat groups also perform similar functions. On these platforms, participants will be more willing to show their side as sexual minorities. Another participant mentioned that he would create a more perfect gay person on Weibo. These explicitly coming out behaviors on the web show the need for participants to be accepted.

Although participants rarely adopted explicitly coming out strategy, they said that it would be very helpful for them to fully disclose to friends. One participant once said that after coming out to a friend, he felt that the friendship between the two was closer. Sexual minority associations on campus and online sexual minority dating software provide participants with a trusted environment for communication. The existence of these communication environments to a certain extent meets the needs of sexual minorities' communication and interaction, but the disconnection of these environments from daily life has left some participants at a loss.

The good news is that all participants did not experience discrimination or bullying in school because of sexual minorities. However, some participants still consider the overall environment of the school to be unfriendly to LGBTQ. The vast majority of participants expressed an expectation that they would have a more open and inclusive university environment without having to worry about the dangers incurred after coming out publicly. Participants now worry that being known by teachers and school staff will affect their access to scholarships and other rewards. Participants also worry that they will be isolated and bullied after being known by classmates and other students. 


\subsection{Impersonation Strategy}

"Impersonation" strategy is a conservative and safe choice, which refers to guiding others to believe that they are heterosexual. "Impersonation" can be divided into "active impersonation" and "passive impersonation". The two seem to be the same, but they have different emotional connotations.

"Active impersonation" is intended to make others believe that they are heterosexual through words and actions. A gay sophomore in medical school told the researchers that when roommates discussed their favorite girls, they would never use the word "girl" for communication, but "partner" for neutral expression. Although the topic is not pleasant to him, he will try to participate in the discussion.

"If I don't talk, they'll think I'm weird. I don't want to be different. But let me completely say lies, I also feel very uncomfortable, so I will use other words to replace the object I pursue. Sometimes I make up stories that are more girlish. "

"When it comes to my boyfriend and me arguing over playing video games, I think this story is too masculine, so when I chat with my roommate, I will replace the reason for this argument with the dispute over a certain entertainment gossip. It seems that the latter is more like the situation that only male and female friends can appear, rather than the story of two boys."

"Passive impersonation" means letting people acquiesce that they are heterosexual and do not correct it. A gay sophomore at the school of psychology told the researchers that although he thought his femininity had become apparent, his best friends never seemed to doubt his sexual orientation. When asked why he didn't disclose his identity, he repeatedly said, "yes, but not necessary."

"There was a time when, for some reason, I often ate with a girl in my class. My good friend often thought I was after her. I thought they were joking, but later I found out that they really thought so, so I admitted that everyone was relaxed."

Both "active impersonation" and "passive impersonation" have a lot of negative effects on their campus life, the most important of which is the separation of campus life and private life. Gay students in the study described the cleavage as "wearing a mask," "erecting a wall," and "feeling schizophrenic". Maintaining this state of fragmentation requires constant vigilance.

They feel that campus life is full of deceit, like wearing a "protective shell". They describe their living conditions in this way: "I need to constantly decide what to tell others and what not to, and worry about where I am seen and with whom outside school." "My self-protection has become so natural that I don't even realize I'm protecting myself." "I can't be an honest man. I feel like a liar. I don't want to be a hypocrite, but I feel like I have to lie. " The self-protection of homosexual students will affect their relationship with their roommates and classmates. "I can't share my personal life. People don't know me. I want them to know that I'm all right and not alone. But my relationship with my classmates is too shallow, because I can't talk about my own life. "
This kind of experience makes gay students feel isolated and alienated in school. Wearing masks at school all day also makes them exhausted. Gay students also feel angry, frustrated and sad about the need to cover up and pretend. "Heterosexuality really doesn't know anything about our homosexual self-protection. I'm angry at the injustices that forced me to lie, and I'm frustrated. "

In addition, homosexual students will feel that they have failed to change people's stereotype of homosexuality and do something for homosexual groups through disguise and pretending. "I feel conflicted. On the one hand, I don't think they need to know who I am. On the other hand, if they do, they can make the world better."

\subsection{Implicitly Coming Out Strategy}

For the seven subjects, two of the interviewees' sexual minority identity management strategy was "implicitly coming out." This means that although the sexual minorities did not disclose their identity to others directly on campus, some people know that they are sexual minorities. The " implicitly come out" strategy is a very subtle strategy. Unlike other strategies above, when they decide to " implicitly come out", they no longer pose as heterosexual identities and cover up. Sexual minorities, but at the same time on campus, they do not choose to actively inform others of their sexual minorities' identity ("explicitly coming out"), nor will they directly recognize their sexual minorities. The grasp of their certainty of the identity tags and the degree of publicity are the particularity of this strategy. Those who choose the " implicitly come out" strategy will take the initiative and be willing to join the Tsinghua University sexual minority campus (Purple), and there will no longer think "whether should I join the sexual minority", "What should I do if others know that I am a sexual minority group", but there will still be some factors that prevent them from choosing to actively inform or fully disclose their sexual minority status. There are two main ones.

The first reason is to avoid unnecessary troubles. This trouble mainly comes from the "outside groups" corresponding to homosexual. Unlike "masking strategies" and "impersonation strategies", People with the "implicitly come out" strategy are not subjectively anxious and upset about whether others know their identity. As one interviewee mentioned, "I never lie about my identity. I don't want to cover it. I don't Disguise, do not make up stories to pretend to be heterosexual, and no longer play this disguised game. "However, they will be troubled by outside groups' attitudes and behaviors (especially negative attitudes and behaviors) after they know their identity. For example, when a group is going out, no one chooses to live in the same room with him after knowing their sexual minority identity, although they have stated that "nothing terrible will happen". On the campus of Tsinghua University, There are still some prejudices against sexual minorities, and some people will put these prejudices into action with sexual minorities, such as isolation, indifference, etc. Therefore, sexual minorities avoid to making some explicitly Strategies for disclosing 
one's identity to avoid unnecessary prejudice and trouble.

The second reason is to avoid the disagreement and "despise" of one's identity, which mainly comes from the inside of the sexual minorities. As one interviewee mentioned, there is a "chain of contempt" in the sexual minorities. That is homosexual-bisexual-queer, and their status decreases in order. In lesbians, Two feminine girls-- one masculine girl and one masculine girl--two masculine girls, in decreasing order of status. The lighter the status, the easier it is to be despised. We don't know why such a scorn chain is formed; However, it can be known that this chain of scorn is common among sexual minorities in Tsinghua University. Therefore, even in sexual minorities, many bisexuals and queers do not explicitly disclose which sexual minority they are. This is to avoid causing others to despise them.

In general, the operating mode of the "implicitly come out" strategy is more like "diet preference": in daily life, someone does not actively talk about what you like to eat, but when asked what you like to eat, you will express yourself truthfully. On the one hand, this strategy allows them to gain a certain degree of security, because their identity is not directly disclosed. On the other hand, compared with the two strategies of "impersonation" and "disguise", Sexual minority members who come out indirectly feel more inner honesty and don't need to lie or do too much self- censorship.

\section{Discussion}

\subsection{Group Secrets}

In campus life, sexual minorities are faced with the pressure of identity leakage. No matter in dormitory field, class field, or teacher field, their identity is rarely mentioned. They hope that their sexual orientation will not affect their work and study. However, when they joined the "Purple community" of Tsinghua University, their WeChat was exposed to the eyes of every member of the community. They took the risk, and any one of them could tell their secrets to others. Sometimes, even in WeChat groups, two students who have known each other for a long time find that each other and oneself are sexual minorities.

But they often have a silent agreement. They understand that their identity is open in the activities of the community, and they are gathered because of this identity, but they are independent individuals. They will never reveal the identity of each other to others. This kind of potential tacit understanding enables them to participate in community activities calmly. But it has to be said that every one of them has a big question in their hearts about whether this unsubstantiated contract is solid or not. They are not peaceful, and the feelings of doubt, worry and fear affect their lives.

In a research about identity management strategies among lesbian and gay educators, none of the teachers is completely in the cabinet. They all believe that at least one person in the school knows their identity, whether through rumours or direct disclosure; at the same time, no teacher is in the cabinet. When the school fully discloses its identities, their sexual orientation has not been publicly recognized by the school community. [20]

Regardless of the identity management strategy adopted by gay teachers, almost all hope to come out directly at school. Some teachers believe that this is possible in the future, and some teachers do not think it is possible to make their identities more public in the school in the future due to their inner fear and lack of school support. The life experience of gay teachers shows that identity management is a complex and continuous decision-making process that requires a balance between a strong inner fear and a desire for honesty. Coming out is not a single event or process, and facing different people in different places requires constant weighing and consideration.

Griffin's research inspired more follow-up research on the identity management of gay teachers. More and more scholars are focusing on gender-minority teachers in different countries and different disciplines, revealing the workplace experience of gender-minority teachers, the campus atmosphere they face, the factors that affect whether they come out, their teaching and research, and their Resistance to mainstream norms. These studies present a lot of shocking facts about the discrimination and exclusion of teachers from sexual minorities in the heterosexual campus environment, and call for the creation of a more diverse and friendly campus environment. From today's point of view, this research published by Griffin in the early 1990s is a bit old. Nearly 30 years have passed. With the development of the gay rights movement in the United States, the living conditions of the gay community in the United States have undergone great changes. Among them, the milestone victory was the legalization of same-sex marriage across the United States in 2015. It is conceivable that if we do this research in the United States today, there will be fewer gay teachers who choose to pretend to be heterosexual, and there will be more who choose to come out directly. These experiences of gay teachers in the United States nearly 30 years ago may not be unfamiliar to gay teachers in China today. What is the status quo of gay teachers in China? Except for a few narratives on the identity management and campus experience of gay teachers in China, there is still a lack of systematic investigation and research.

\subsection{Next Step: Identity Management Strategy on the Internet}

Our participants socialize on the web in three main ways: dating apps, WeChat groups, and Weibo.

Dating apps: The dating apps used by gays and lesbians are different. But both apps can filter appointments based on distance. So, on the dating app, you can meet a lot of students from same school, same department and even students who live in the same dormitory building.

The identity management strategy on dating apps is to protect themselves while showing themselves. On the app, participants can display a lot of information, including sexual orientation, age, height, photos and even real names, which all depend on the personal wishes of the participants. Most 
participants provided only a pseudonym and a few selfies. At the same time, in order to attract potential date targets, participants will show more of their interesting side. They will tell interesting things in their lives, share their emotional changes, and show their interests and achievements.

Of the seven participants, five reported using dating apps and one found a soul mate on it.

WeChat groups: Participants were all in the WeChat group of purple, and some participants also mentioned joining other WeChat groups. In the WeChat group, they may meet acquaintances who have not come out in reality. At this time, the two sides will keep a shared secret and will not easily mention it in real life.

The identity management strategy in the WeChat group is to show less basic personal information and more exchange of ideas. Participants will discuss their views on the legalization of same-sex marriage and the plight of sexual minorities in reality in the WeChat group. Because trusting others will not speak out, participants can show more real inner thoughts in the WeChat group. Even these ideas are sometimes impractical.

Weibo: Like Twitter in the US, Weibo is a platform for self-explanation. The function of social interaction is not same as the other two. One of our participants said: "I will set up a more perfect gay profile in Weibo. For example, I will repost some more irritating pictures or make some more feminist remarks. If there is in the comments other sexual minorities praised me, I would be very happy and would like to communicate with them."

In Weibo, participants tend to build an idealized self-image, more extroverted and more expressive, this image is difficult for them to have in real life. The establishment of idealized self-images meets some of their identified needs. It is also a supplement, a way to relieve stress. Participants who adopt passing strategies, covering strategies or implicitly coming out strategies lack channels to talk in reality. Post bars and forums also assume functions similar to Weibo. Another participant said, "There are so many homosexuals in a public forum, we call each other sisters, and use some secret symbol that only we know about freely discussing homosexuality."

Identity Management Strategies in the Network: Anonymity, Trust, and Explicitly Coming Out Strategies. The identity management strategy on the Internet is different from reality. Students' assessment of risk and perception of the environment are different. It may be a brand-new strategy. The next research can focus on this aspect.

\section{Conclusion}

"Now everything abnormal before has an answer." These words describe subjects themselves. "I can't get married legally in China!" These words are related to their social life.

Referring to the self-categorization theory, LGBT students' gender identity consists of two parts: a personal identity and a social one. They are pretty different. Correct and rich information is very helpful for personal identity. Bad information, not only unhelpful, but lead their identity to a wrong way.

In this study, the path of personal identity: realization $\rightarrow$ information $\rightarrow$ identity, Which is really different from the previous theories: (perception $\rightarrow$ confusion $\rightarrow$ presupposition $\rightarrow$ fixed) or (same-sex attraction $\rightarrow$ self-labeling $\rightarrow$ same-sex sexual contact $\rightarrow$ self-disclosure). This is because our path is for subjects who are nearly successful personal identity. They do not want to be gay or turn to be gay, they just realize who they are. Positive and Neutral environment little inflected personal identity. When they realized, personal identity started but social identity not. So Social identity and personal identity can be done at different time. One can be highly personal identity but little social identity. There is no obvious sign that personal identity has been completed.

The next research will focus on the identity management strategy on the Internet.

\section{Limitations}

Sample bias: The limited number of samples leads to low representation of the conclusions. Furthermore, Since the subjects who use passing or covering strategy may not be willing to participate in the interview, our part of the conclusion may not be complete.

\section{References}

[1] (2008) Self-Identity. In: Kirch W. (eds) Encyclopedia of Public Health. Springer, Dordrecht.

[2] Aronson, E.; Wilson, T.; Akert, R. (2007). Social Psychology. New York: Pearson Prentice Hall. p. 113.

[3] Guimond, Serge; Chatard, Armand; Martinot, Delphine; Crisp, Richard J.; Redersdorff, Sandrine (2006). "Social comparison, self-stereotyping, and gender differences in self-construal". Journal of Personality and Social Psychology. 90 (2): 221-242.

[4] Morris, Edward W. 2006. An Unexpected Minority. New Brunswick, New Jersey: Rutgers University Press.

[5] Lewis, Amanda E. 2003. Race in the Schoolyard: Negotiating the Color Line in Classrooms and Communities. New Brunswick, New Jersey: Rutgers University Press.

[6] Gibson, Margaret, Patricia Gandara and Jill Koyama. 2004. School Connections: U.S. Mexican Youth, Peers, and School Achievement. New York: Teachers' College Press.

[7] Barrett, B., \& Logan, C. (2002). Counseling gay men and lesbians: A practice primer. Pacific Grove, CA: Brook/Cole.

[8] Roberts, M., \& University of North Texas. (2002). Sexual Orientation Self-label, Behavior, and Preference: College Students in Taiwan and the United States of America., Source: Dissertation Abstracts International, Volume: 63-09, Section: B, page: 4384 .

[9] Doyle, J. M., \& Kao, G. (2007). Are racial identities of multiracials stable? Changing self-identification among single and multiple race individuals. Social Psychology Quarterly, 70, 405-423. 
[10] Rivers, I., Gonzalez, C., Nodin, N., Peel, E., \& Tyler, A. (2018). LGBT people and suicidality in youth: A qualitative study of perceptions of risk and protective circumstances. Social Science \& Medicine, 212, 1-8.

[11] Cole, C., \& Harris, H. (2017). The Lived Experiences of People Who Identify as LGBT Christians: Considerations for Social Work Helping. Social Work and Christianity, 44 (1/2), 31-52.

[12] Zhang Beichuan. Same-sex love [m] Jinan: Shandong Science and Technology Press, 1994.

[13] Shi Guozheng, Kang Laiyi, Chen Donghua, Zhang Yong, Yin Fanglan, Zha Yanfen, Mao Jun, Zhuang Qin, Steele SJ, Myers $\mathrm{T}$.

[14] Li Yinhe. The feelings and sex of Chinese women [m]. Beijing: China Friendship Publishing Company, 2002: 204-222.
[15] Li Yinhe. Gay subculture [m]. Beijing: China Friendship Publishing Company, 2002. 1.

[16] Liu Dalin, Lu Longguang. Chinese homosexual research [m]. Beijing: China Social Press, 2005.

[17] Zhou Lingang. A Review of Social Support Theory [J]. Journal of Guangxi Teachers College (Philosophy and Social Sciences) Edition, 2005, 26 (3): 11-20.

[18] Zhang Peifei: Research on Homosexual Identity, Southwest University Master's Thesis 2014.

[19] Effective Literacy Practices and Challenging Curriculum for At-Risk Learners: Great Expectations.

[20] Pat Griffin. (1991). Identity management strategies among lesbian and gay educators. International Journal of Qualitative Studies in Education (3). doi: 10.1080/0951839910040301. 